\title{
Buried Waste Integrated Demonstration Test Objectives
}

John L. Morrison

Robert E. Heard

Published May 1993

\author{
Idaho National Engineering Laboratory \\ EG\&G Idaho, Inc. \\ Idaho Falls, Idaho 83415
}




\section{Buried Waste Integrated Demonstration \\ Test Objectives}

EGG-WTD-10878

Prepared by
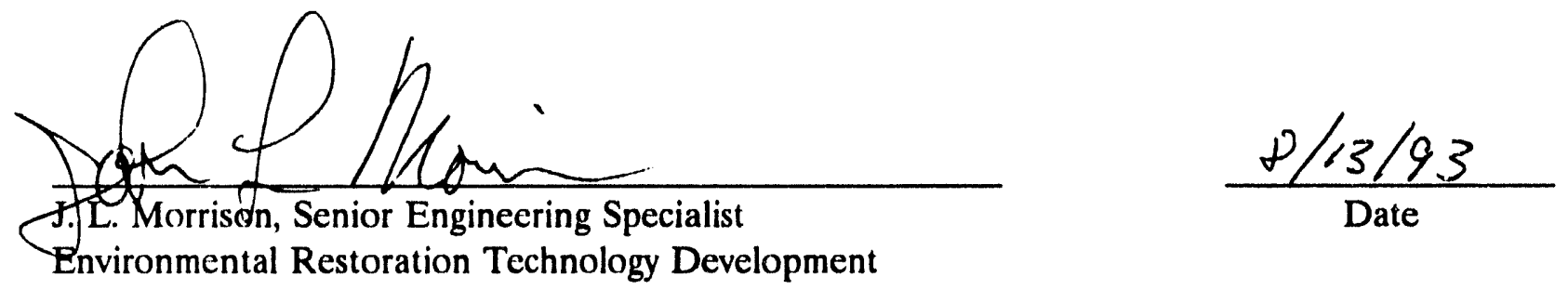

Reviewed by

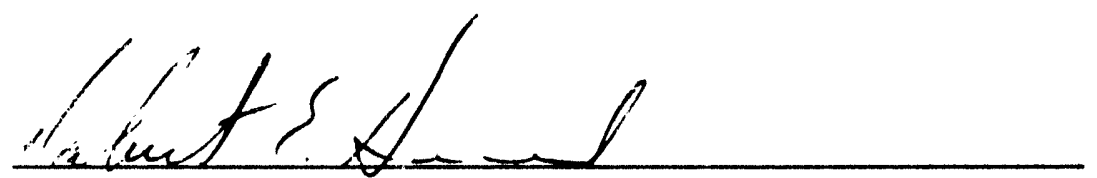

R. E. Heard, Project Manager

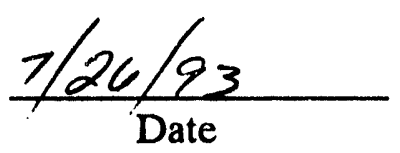

Buried Waste Integrated Demonstration

Approved by
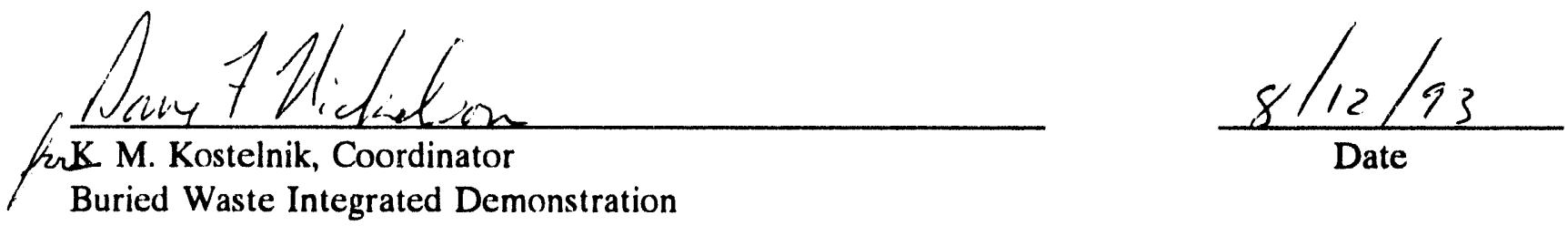

Buried Waste Integrated Demonstration 


\begin{abstract}
The mission of the Buried Waste Integrated Demonstration Program (BWID) is to support the development and demonstration of a suite of technologies that when integrated with commercially available baseline technologies form a comprehensive system for the effective and efficient remediation of buried waste throughout the U.S. Department of Energy complex. To accomplish this mission of identifying technology solutions for remediation deficiencies, the Office of Technology Development initiated the BWID at the Idaho National Engineering Laboratory in fiscal year (FY) 1991. This document provides the test objectives against which the demonstrations will be tested during FY-93.
\end{abstract}




\section{SUMMARY}

During the summer of 1993, the Buried Waste Integrated Demonstration (BWID) project will perform a number of demonstrations that test retrieve/ex situ and thermal treatment technologies, which include mobile radiochemistry laboratory, remote characterization platform, mobile decontamination and fixant dispenser, manned overburden removal system, and remote excavator.

This document provides the (a) overall objectives for the core system, which at this level are technology independent and focus on the function rather than implementation, (b) subelement test objectives directly related to the core system objectives, and (c) technical test objectives for the technology that will be demonstrated. 


\section{CONTENTS}

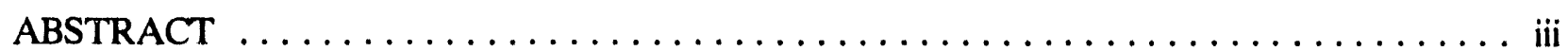

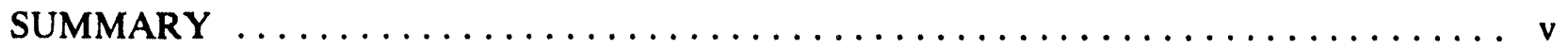

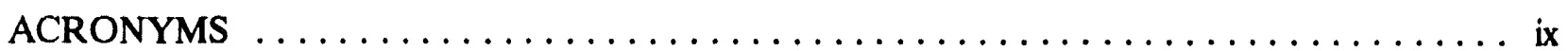

1. INTRODUCTION $\ldots \ldots \ldots \ldots \ldots \ldots \ldots \ldots \ldots \ldots \ldots \ldots \ldots \ldots \ldots \ldots \ldots \ldots$

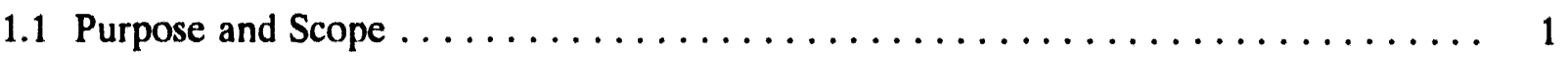

2. DEMONSTRATION DATA MANAGEMENT $\ldots \ldots \ldots \ldots \ldots \ldots \ldots \ldots \ldots, 2$

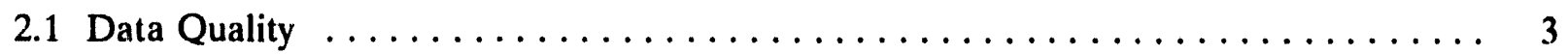

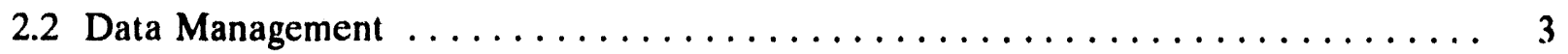

3. BURIED WASTE RETRIEVAL/EX SITU THERMAL TREATMENT

CORE SYSTEM OBJECTIVES $\ldots \ldots \ldots \ldots \ldots \ldots \ldots \ldots \ldots \ldots \ldots \ldots, 4$

3.1 Functional Subelement 1.0 Site/Waste Characterization $\ldots \ldots \ldots \ldots \ldots \ldots \ldots, 4$

3.1.1 Background Technical Information $\ldots \ldots \ldots \ldots \ldots \ldots \ldots \ldots \ldots \ldots, 4$

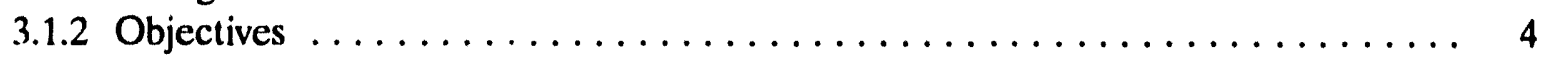

3.2 Functional Subelement 2.0 Belowgrade Isolation $\ldots \ldots \ldots \ldots \ldots \ldots \ldots \ldots, 6$

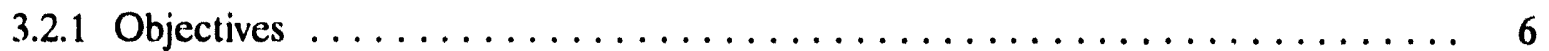

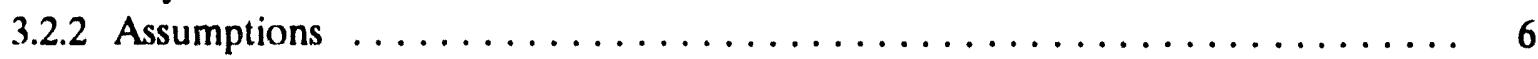

3.3 Functional Subelement 3.0 Abovegrade Containment $\ldots \ldots \ldots \ldots \ldots \ldots \ldots$. 6

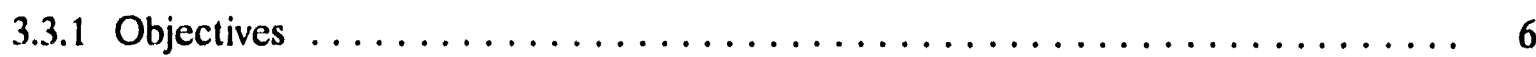

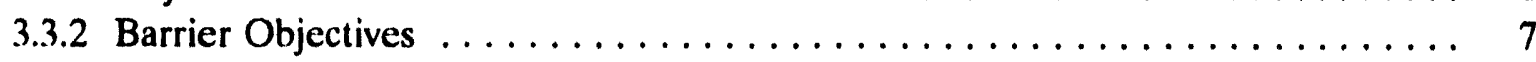

3.4 Functional Subelement 4.0 Overburủen Characterization/Removal $\ldots \ldots \ldots \ldots, 8$

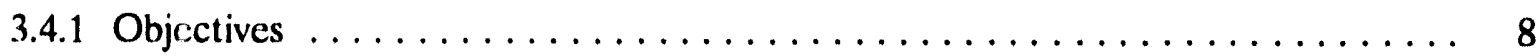

3.5 Functional Subelement 5.0 Retrieval $\ldots \ldots \ldots \ldots \ldots \ldots \ldots \ldots \ldots, \ldots$

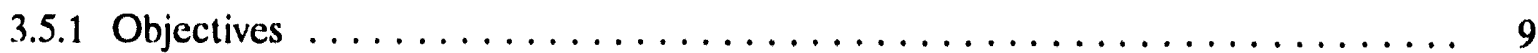

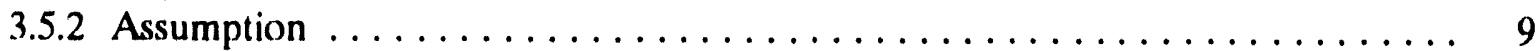

3.5 .3 Waste Retrieval .............................. 10

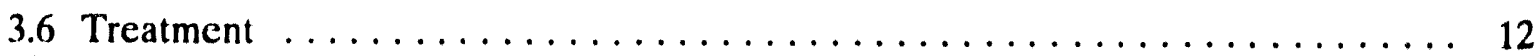


3.6.1 Background Technical Information $\ldots \ldots \ldots \ldots \ldots \ldots \ldots \ldots \ldots \ldots \ldots$

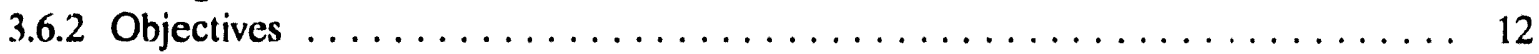

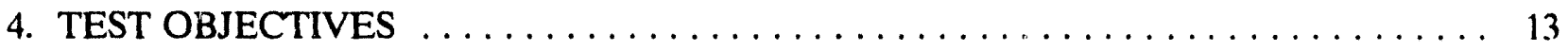

4.1 Site/Waste Characterization Technology Demonstration Test Objectives . . . . . . . 13

4.2 Belowgrade Isolation Technology Demonstration Test Objectives $\ldots \ldots \ldots \ldots \ldots \ldots$

4.3 Abovegrade Containment Technology Demonstration Test Objectives $\ldots \ldots \ldots \ldots 14$

4.4 Overburden Characterization and Removal Technology Demonstration

Test Objectives .............................. 16

4.4.1 Overburden Characterization Demonstration $\ldots \ldots \ldots \ldots \ldots \ldots \ldots \ldots$

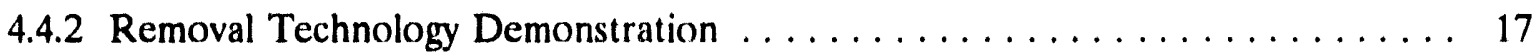

4.5 Retrieval Technology Demonstration Test Objectives $\ldots \ldots \ldots \ldots \ldots \ldots \ldots \ldots$

4.6 Treatment Technology Demonstration Test Objectives . . . . . . . . . . . . 19

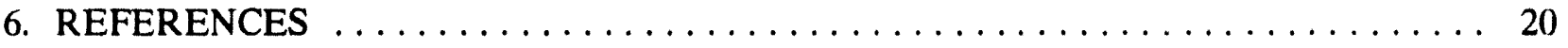

Appendix A-FY-93 Technology Test Objectives $\ldots \ldots \ldots \ldots \ldots \ldots \ldots \ldots \ldots \ldots$ A-1

FIGURE

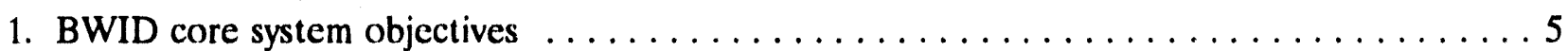




\section{ACRONYMS}

BWID Buried Waste Integrated Demonstration

CAM Continuous air monitors

CTP Cold Test Pit

DAC Derived air concentration

DOE U.S. Department of Energy

ER\&WM Environmental Restoration and Waste Management

FY Fiscal year

INEL Idaho National Engineering Laboratory

LAMS Lifting and Moving System

MTBF Mean time between failures

OTD Office of Technology Development

Pl Principal investigator

RWMC Radioactive Waste Management Complex

SDA Subsurface Disposal Area

TCLP Toxicity Characterization Leaching Procedure

TRU Transuranic

UBC Uniform Building Code

UCRL University of California, Lawrence Radiation Laboratory 


\section{Buried Waste Integrated Demonstration Test Objectives}

\section{INTRODUCTION}

The U.S. Department of Energy (DOE) Office of Technology Development (OTD) Buried Waste Integrated Demonstration (BWID) program is supporting the development and demonstration of a suite of technologies that when integrated with commercially available baseline technologies form a comprehensive system for the effective and efficient remediation of buried waste throughout the DOE complex.

During each fiscal year (FY) BWID will oversee a number of field and or laboratory demonstrations. After each demonstration, the data collected will be shared with the Environmental Restoration and Waste Management (ER\&WM) offices throughout the DOE complex. To ensure proper and adequate data collection, the BWID has worked with the ER\&WM offices to establish a minimum set of objectives that will be used to guide technology testing. These minimum objectives should not limit test data but will provide a common ground to evaluate how well a technology can satisfy the needs of ER\&WM.

\subsection{Purpose and Scope}

The purpose of this document is to specify those minimum test objectives from the highest overview level down to the detailed objectives required for an individual technology. Section 3 provides the high-level test objectives. The objectives in this section are generic and represent the concepts of the buried waste retrieval/ex situ thermal treatment configuration option as detailed in the INEL Operable Unit 7.13 Retrieval/Ex situ Thermal Treatment Configuration Options Report'.

Section 4 of this document provides the next lower level (more detailed) test objectives for each element within the buried waste retrieval/ex situ thermal treatment configuration. These objectives provide the basis for individual technology test plans. Each technology to be demonstrated will address those objectives relevant to that technology and establish test plans accordingly.

Appendix A contains the BWID-required test objectives for an individual technology. Appendix $A$ only addresses technologies that are to be demonstrated during FY-93. Each technology test plan must address each objective specific to that technology as detailed in Appendix A. This document will be updated in FY-94 to address specific technology test objectives for FY-94 BWID-sponsored technology demonstrations. 


\section{DEMONSTRATION DATA MANAGEMENT}

Test design demonstrations that are developed will contain full details of the testing. These test design details shall be documented in a test plan that includes the following, where applicable:

- Test evolution design

- Specific measurements of the system response

- Measurement analysis of expected system response (bandwidth, dynamic range, and acceptable uncertainty)

- Measurement duration and data storage requirements

- Quick look evaluation criteria

- Measurement system design and analysis

- Sensors

- Signal conditioners

- Analog to digital conversion

- Sample rates

- Multichannel synchronization

- Reference clock

- Data storage (acquisition and mass)

- System diagnostics

- Measurement error analysis

- Data processing software

- Quick look and/or reality check

- Final processing

- Diagnostic software

- Detailed operating procedures

- Failure evaluation, reporting, and system retest

- Test personnel qualifications

- Test site preparations

- Data handling and processing procedures

- Reporting requirements, etc.

Technical validation of the demonstration test design will be accomplished through various levels of review. The first review level will be a peer review of the high-level test plans, which will indicate what system exercises are necessary for an adequate technology demonstration. The second level of review will be a peer review of the detailed test design, which is a multifaceted review covering each 
of the items listed above and other test plan items as described in Reference 2. The third level of review is a readiness review, which is a review by a subset of the reviewers of the detailed test design. The third review will focus on operational aspects of the test to ensure that everything necessary to make the test happen successfully and safely is in place. The last review is the quick-look check of the data, where the results of system exercises are reviewed to determine if the data are credible and if any test should be repeated before a test setup is disassembled. The infield review will deal with system failures as they occur during actual field demonstration. A technical evaluation of the system failure and recommended corrective action will be presented to the project manager for a decision to implement the recommendation or stand down the test. The last review ensures the technical credibility of the results and is published in a journal.

\subsection{Data Quality}

All BWID demonstration testing shall be done in accordance with an approved test plan, approved test procedures, and qualified personnel (as delined in the procedures). The test procedures shall specify sensor and measurement systems to be used (model number, make, calibration, etc). Measurement uncertainty for data taken against BWID test objectives shall be documented.

\subsection{Data Management}

Each demonstration technology shall comply with the following BWID data management policy:

- Electronic Data

- Each demonstration technology shall define the format, acquire the data, back up the data, configuration control the data, technically document the data, generate processed data, and archive the data on the BWID data management system.

- Each demonstration technology shall submit to BWID any requested copy of configuration controlled data (raw or processed) and appropriate technical documentation during the demonstration testing. Each demonstration technology shall submit complete copies of final configuration controlled raw and processed data with appropriate technical documentation to BWID with the final report.

- Reports

- Each demonstration technology shall draft reports, obtain and incorporate review comments, and obtain approvals, archive, and configuration control through a technology demonstration file.

- Configuration controlled copies of draft reports shall be submitted to BWID as requested. Copies of all final reports shall be submitted to BWID with an electronic copy. 


\section{BURIED WASTE RETRIEVAL/EX SITU THERMAL TREATMENT CORE SYSTEM OBJECTIVES}

The objectives outlined in this section were obtained from Reference 1. The objectives for "Waste Characterization" and "Below-grade Isolation" were taken as is; the objectives for "Above-grade Containment," "Overburden Removal," and "Retrieval" were modified significantly to transform them into a more generic and less technology-specific form. These objectives fit the BWID core system as shown in Figure 1.

\subsection{Functional Subelement 1.0 Site/Waste Characterization}

\subsubsection{Background Tochnical Information}

The transuranic (TRU) waste pits and trenches are located at the Idaho National Engineering Laboratory (INEL) Subsurface Disposal Area (SDA) (Pits 1-6, 9-10 and Trenches 1-15, 19, 32). The TRU waste pits were excavated to the underlying basalt layer and generally backfilled with 2 to $5 \mathrm{ft}$ of soil to provide a level floor. The TRU waste trenches were generally excavated to the basalt layer, approximately $10 \mathrm{ft}$ down and averaging $7 \mathrm{ft}$ wide and up to $1,800 \mathrm{ft}$ long. Following excavation, wastes were placed or dumped into the pits and trenches. From 1952 to 1963, the waste containers were stacked to optimize disposal space. Between 1963 to 1969, the waste packages were randomly dumped into the pits and trenches to limit worker radiation exposure. In 1969, the waste containers were again stacked to optimize disposal volume. Once emplaced, the wastes were backfilled and covered with silty clay and sandy soil.

Physical dimensions of each waste pit and trench (including overburden) are given in Tables 1 and 2 of Reference 1. The characteristics of the INEL Radioactive Waste Management Complex (RWMC) soils are given in Tables 4 through 8 of Rcference 1.

\subsubsection{Objectives}

The objectives of this subelement are to

- Determine the original vertical boundaries of the waste pits and trenches within $\pm 2 \mathrm{ft}$;

- Determine the depth of the basalt underlying the original vertical boundaries of the waste pits and trenches within $\pm 2 \mathrm{ft}$.

- Determine the depth to overburden and waste interface for each waste pit and trench within $\pm 2 \mathrm{ft}$.

If these objectives are met, the estimated boundaries of the regions to be remediated (waste seams) will be known. 


\section{BWID's FY93 Program Consist of 14 Technology Demonstratior and 6 Research Efforts}

Site/Waste

Characterization

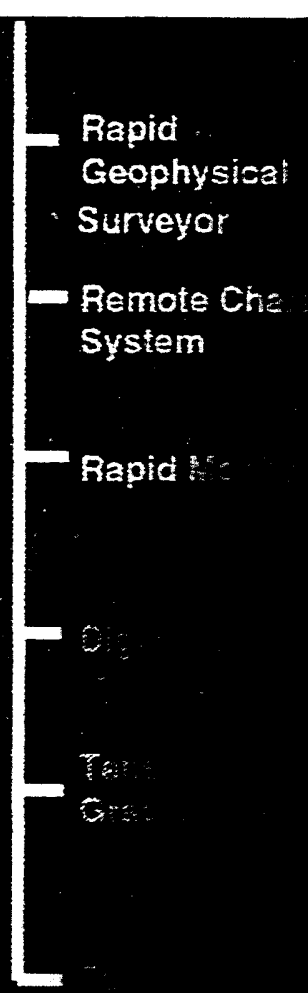

Below Grade

Isolation

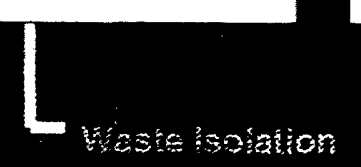

Waste folation
Contamination

Control Unit

Natura!

Polys $\equiv:$

Above Grade

Containment

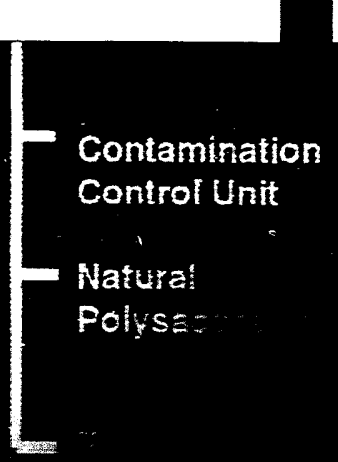

Overburden

Characterization

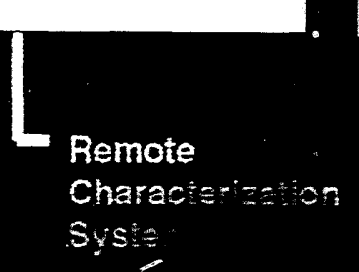

Retrieval

Removal

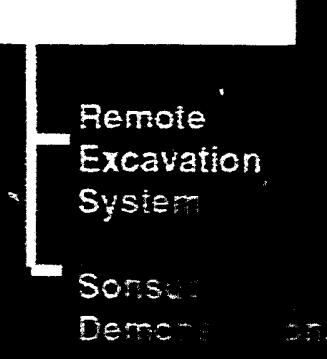

Treatment

Remote

- Excavation

System

Caterpiltar

Demonstration
DC Graphite Mark II

- USBh ARC Meiter

'Fetech Furnace

MSE Centrifugal Furnace

Waste 


\subsection{Functional Subelement 2.0 Belowgrade Isolation}

\subsubsection{Objectives}

This subelement will meet the following objectives:

- The boundaries or regions to be remediated will be surveyed, and an institutional review will establish the estimated boundaries. This review will define the waste seam boundaries and will include some margin in addition to the estimated boundary values.

- Engineered barriers will be constructed extending from the surface and anchored to the underlying basalt to provide belowgrade isolation of the area to be remediated.

- The belowgrade isolation barriers must provide complete structural integrity if $100 \%$ of the contained waste volume is removed.

- An angle of repose will be avoided to minimize the amount of soil side burden to be excavated.

- The engineered barriers of choice may be used for the foundation of any abovegrade containment structure.

If these objectives are met, belowgrade barriers will be installed that bound the areas or regions to be remediated.

\subsubsection{Assumptions}

It is assumed that leakage through the barriers will be mitigated by INEL RWMC site renovations (surface flooding mitigation) performed under the 300-year flood drainage program. It is also assumed that the subsurface basalt is always at a depth less the $9.5 \mathrm{~m}$.

\subsection{Functional Subelement 3.0 Abovegrade Containment}

\subsubsection{Objectives}

The following objectives will be met for this subelement:

- Belowgrade barriers will be installed bounding the areas or regions to be remediated.

- Abovegrade containment structures shall encompass the entire waste pit or trench to be excavated.

- Abovegrade containment structures shall be designed to comply with the following standards: Design and Evaluation Guidelines for Department of Energy Facilities Subjected to Natural Phenomenon Hazard. ${ }^{3}$ U. S. Department of Energy Idaho Operations Office (DOE-ID) 
DOE-ID Architectural Engineering Standards, ${ }^{4}$ Operational Safety Design Criteria Manual, ${ }^{5}$ and the industry standard Uniform Building Code (UBC).

- Entire abovegrade containment shall have a facility classification of moderate hazard in accordance with University of California, Lawrence Radiation Laboratory (UCRL)-15910. ${ }^{3}$

- Region between the barriers shall be continuously monitored to ensure integrity of the barriers. Monitoring may include differential pressure, air flow, and contamination detection.

- Region between the barriers shall be accessible for maintenance activities such as decontamination and leak repair.

- Barrier system shall be designed so that flow though a breech in the barrier is always inward and away from the outside environment.

- Any exhaust air flow from the barrier system will be directed up an appropriately sized stack and will comply with all Federal emissions' objectives.

\subsubsection{Barrier Objectives}

Containment may involve the erection of three separate barriers to mitigate the movement of contaminants. The INEL building construction standards listed above, including fire protection systems and safety items, applies to each barrier.

- Barrier 1 (outer barrier)

- The barrier shall be a weather shield that meets all local INEL environmental objectives such as sunlight, humidity, temperature, snow loading, winds, rain, hail, and earthquakes.

- The inside of the weather shield shall be constructed of material that resists the accumulation of contamination and is easily decontaminated.

- The weather shicld shall have an air lock that penetrates through the middle barrier and is adequately sized to allow ingress and egress of all the retrieval system equipment.

- The weather shicld shall have a personnel air lock that penetrates through the middle barrier and allows ingress and egress for maintenance or operational activities by personnel wearing bubble suits.

- Barrier 2 (middle barricr)

- The barrier shall be located internal to the weather shicld.

- The spacing between the middle barrier and weather shield will be kept to a minimum, which will maximize the inner working area while minimizing the overall size of both barricrs. 
- The middle barrier shall be constructed of material that resists the accumulation of contamination and is easily decontaminated.

- The middle structure shall be designed to be compatible with support systems such as fire protection, lighting, and communication in accordance with the requirements outlined in the DOE-ID Architectural Engineering Standards. ${ }^{4}$

- Barrier 3 (inner barrier)

- The barrier shall be located directly over and completely enclosing the area undergoing retrieval operations.

- The region between the middle and inner barriers shall be large enough to be used as a staging area for maintenance or atypical waste operations.

- The inner barrier material shall be constructed of material that resists the accumulation of contamination and is easily jecontaminated.

- The area immediately outside the inner barrier shall be continuously monitored and operationally controlled for contamination.

- The inner barrier shall have access ports to the remediation area that allow ingress or egress of the equipment necessary to support retrieval operations.

If these barrier objectives are met, containment facility will be completely installed and operational over the region that will undergo retrieval operations.

\subsection{Functional Subelement 4.0 Overburden Characterization/Removal}

\subsubsection{Objectives}

The following objectives will be met for this subelement:

- Overburden Characterization

- Before any removal of overburden, a characterization of the overburden shall be conducted to locate any TRU and/or hazardous hot spots. Characterization techniques must be able to sample for TRU and hazardous contaminants found in Table 2 of Reference 4.

- Contaminated (TRU and hazardous) overburden shall be carefully removed (either by manual or remote excavation) and temporarily stored. This overburden shall be added to the retrieved waste and shipped for treatment. 
- Overburden characterization equipment must have the capability to detect $\operatorname{TRU}^{1}$ and hazardous constituents found in Table 2 of Reference 4.

- Overburden Removal

- After characterization and hot spot removal, the remaining overburden will be retrieved in layers not to exceed the depth where characterization is certain to detect any hot spots.

- After retrieving a layer of overburden, characterization of the remaining overburden shall be performed before another layer is removed. This process will be repeated for each layer of overburden removed.

- Overburden removal equipment shall not cause the level of airborne contamination to exceed the limit for access by personnel wearing bubble suits.

- Overburden removal equipment must complete overburden removal of a t. pical (about the size of Pit 9 at the RWMC SDA) pit or trench within a 2-week period.

- Down to $0.3 \mathrm{nCi} / \mathrm{g}$

- Retrieved overburden, other than hot spots, shall be packaged and removed from the containment. This overburden shall be stored under a weather shield for further test and evaluation.

- After the final layer of overburden is removed, the entire retrieval surface will be treated to immobilize contamination.

- Up to $75 \%$ of the estimated or surveyed overburden (depth) shall be removed. The remaining $25 \%$ of the overburden shall be left in place to minimize exposing waste.

If these objectives are met, $75 \%$ of the overburden will be removed, and the retrieval area will be stabilized to immobilize contamination spread.

\subsection{Functional Subelement 5.0 Retrieval}

\subsubsection{Objectives}

For this subelement, a containment facility over the region to be remediated, and $75 \%$ of the overburden will be removed. The objective is to remove all remaining overburden and waste from the pit and/or trench and control the spread of contamination during the packaging process.

\subsubsection{Assumption}

It is assumed that criticality can be prevented. The occurrence of an unplanned criticality is an important issue, and reasonable efforts shall be taken to avoid this unlikely event. The Buried Waste Program has limited the retrieval batch, sized to $1.4 \mathrm{yd}^{3}$ with a possible extension to $2 \mathrm{yd}^{3}$. This is 
based on a the latest evaluation of the waste sent to the INEL from the Rocky Flats Plant. Limiting the batch size and disallowing batches to be commingled are considered an extremely conservative approaches. For BWID, the batch size will be limited to $2 \mathrm{yd}^{3}$.

\subsubsection{Waste Retrieval}

- Instrumentation capable of online, real-time identification of atypical wastes (physical dimensions greater than $4 \times 4 \times 8 \mathrm{ft}$ beta/gamma) shall be used during retrieval operations.

- As mentioned in Reference 6, atypical wastes may be relocated within the pit or trench and sprayed with a fixant material to suppress contamination spread. Normal retrieval activities may proceed, and the atypical $v$ sste bypassed until its removal can be planned.

- Exposed basalt, after a section of the pit or trench has been excavated, shall be sprayed with a fixant to control dust during the remaining retrieval operations.

- The waste retrieval operation shall be remote controlled with maintenance performed by personnel wearing bubble suits.

- The excavator and any conveyance system shall be remote controlled and have the following features:

- System shall be capable of excavating and moving $80 \mathrm{yd}^{3}$ of soil and/or waste mix in an 8-hour period.

- Retrieve and conveyance cycle shall not contribute to the spread of contamination.

- Remote systems shall have force feedback in their control networks.

- Excavation system shall be capable of removing up to $2 \mathrm{yd}^{3}$ of soil and/or waste mixture per operation.

- Primary system input power shall be electrical. All power and control systems inside the containment structure shall be explosion proof. Secondary power derived from the primary electrical power shall not involve any internal combustion process.

- Excavation system shall be capable of distributing its weight to prevent cave-in at the excavation face.

- Excavation system shall have manual pendent controls and be compatible with operations that require personnel wearing bubble suits.

- $\quad$ Mean time between failures (MTBF) $>=1,000 \mathrm{~h}$.

- A remote video system shall provide for adequate visual control of all operations. 
- The control room for remote operations will be located up to 500 ft away from the retrieval area. The control room shall be adequately shiclded (against all anticipated accident scenarios) for radiation and hazard exposure to operations personnel.

- A contamination control system shall be provided to keep the contamination levels within the limits that allow personnel wearing bubble suits to enter for maintenance and special operations.

- A remote-operated contamination control system shall be able to transverse the entire regions, internal to the inner barrier, to dispense fixants, misting agents, encapsulant, and dust suppression agents.

- The dispensed contamination control agents or fixants shall have the following objectives:

- Form a barrier to immohilize contamination and prevent its spread

- Compatible with the excavation and conveyance system

- Fast operating cure time and compatible $v$ th excavation and conveyance operations

- Cure into a product that is nonhazardous and compatible with waste treatment

- Dispensed by means of nonhazardous and nonflammable liquid.

- The contamination control system shall have total $x-y-z$ access to all positions in the inner barricr.

- A rapid contamination monitoring system shall be provided to allow continuous monitoring of contamination levels. Contamination levels shall be held within the limits for access that requires personnel wearing bubble suits. The rapid contamination monitoring system shall have the following features:

- System shall be controlled from and housed in a mobile laboratory. The laboratory shall be located outside the containment. The system's function is to process various coupons, swipes, and samples brought from containment area.

- System shall be capable of analyzing at least 100 samples per day at $10 \mathrm{pCi} / \mathrm{g}$ accuracy for ${ }^{239} \mathrm{Pu}$.

- System shall be simple enough so that trained technicians may operate it.

- System shall have alpha continuous air monitors (CAMs) distributed throughout the containment facility, including the retricual areas. CAMs shall have remote sensing heads.

- CAMs shall be able to measure ${ }^{239} \mathrm{Pu}$ to the required accuracy in a high thorium and or radon background of 1-Derived Air Concentration (DAC)-h. 
- Within the containment facility, a lifting and moving system (LAMS) shall be provided with the following features:

- Remote operated with the same kind of operations and control features as the remote excavation system.

- Capable of relocating, within the inner barrier, overweight or oversized objects that cannot be processed with the excavator.

- Capable of moving special equipment necessary to stabilize, shield, or size reduce any oversize or overweight objects.

- Capable of deploying various equipment within the inner barrier as necessary.

If these objectives are met, hazardous, TRU, mixed, low-level, and contaminated soil will be retrieved. ${ }^{6}$

\subsection{Treatment}

\subsubsection{Background Technical Information}

Waste material shall be excavated from the TRU waste pits and trenches located at the INEL SDA (Pits 1-6, 9, and 10 and trenches 1-15, 19, and 32). The material will be packaged and assayed to ensure safety from a criticality accident. The packaged waste will be shipped to a thermal treatment facility. The thermal treatment will provide volume reduction and destruction of all organic materials.

\subsubsection{Objectives}

The objectives of this subelement are

- Processing of waste shall prevent any possibility of criticality.

- System shall be operationally safe from explosions, firc, radiation, or hazardous materials exposure.

- Processing shall destroy all organic material.

- System shall be capable of processing waste material at or greater than 14 tons/day.

- Processing shall not result in volume increase.

- System design shall control contamination spread from beta, ga:nma, alpha, and hazardous material to allow maintenance and/or repair operations by personnel in bubble suits

If these objectives are met, the treated waste will be in a form free of any organic matcrial and with no possibility of becoming critical. 


\section{TEST OBJECTIVES}

The following test objectives apply to the subelements of the Core System Block Diagram of Figure 1. These test objectives are derived from the core system objectives listed in Section 3. The test objectives provide guidance for the principal investigator (PI) who is responsible for demonstrating the various technologies associated with the core system. This guidance should help the PIs draft their technology demonstration test plans. These test objectives are not meant to restrict the scope of the technology demonstration tests but rather provide issues that each of the demonstration technologies should attempt to address. Specific technologies are not likely to address all the issues of its subelement. The responsible PI must address the appropriate subset of test objectives relevant to their technology. The PI may supplement these with additional test objectives deemed relevant to configure that particular demonstration technology test plan.

\subsection{Site/Waste Characterization Technology Demonstration Test Objectives}

The test objectives for this subelement are

- Assess the ability to identify and locate the original excavation pit boundaries. The output will be as follows:

- Pit boundary characteristics and the probability that the technology will indicate the boundary associated with those characteristics.

- Accuracy and repeatability of the technology to locate the pit boundaries associated with the particular pit boundary characteristics.

- Assess the ability to identify the basalt layer beneath the pit boundary and determine the depth to the basalt. The output will be as follows:

- Soil characteristics and the probability that the technology will indicate the buried basalt layer with those soil characteristics.

- Accuracy and repeatability of the technology to measure the depth to the buried basalt layer with the particular soil characteristics.

- Assess the ability of the system to measure the depth to the transition from overburden to buried waste debris. The output will be as follows:

- Soil characteristics and the probability that the system will indicate depth to overburden and/or waste interface.

- Accuracy and repeatability of the system measurement to the overburden and/or waste interface with the particular soil characteristic. 
- Assess the capability of the technology to function in the expected environmental conditions. The output will be the measurement of technology performance against the expected environment variables (temperature, season, dust, wind, etc.).

- Assess the response time and cost of the technology to perform its function. The output will be as follows:

- Measurement of how long it took to gather the data and how long it took to get the data reduced.

- Measurement of labor hours to gather and reduce data.

- Assess the system reliability concerning its ability to fulfill the intended function. The output will be documentation of mission degrading problems encountered because of equipment breakdown and design deficiencies.

\subsection{Belowgrade Isolation Technology Demonstration Test Objectlves}

The test objectives for this subelement are

- Assess the ability to place the belowgrade isolation at the desired location. The output will be a comparison of surveys of the actual location with the desired location.

- Assess the ability of the belowgrade isolation to be anchored to the buried basalt layer and provide structural support to mitigate any possibility of cave-ins when the waste seam side of the isolation is excavated. The output will be to

- Perform waste seam side excavations.

- Examine the basalt anchors record observations.

- Stress the nonwaste side of the wall with heavy equipment or perhaps irrigation and record results of any degradation.

\subsection{Abovegrade Containment Technology Demenstration Test Objectives}

The test objectives for this subelement are

- Assess the ability of the weather shield to function in the expected environmental conditions (temperature, precipitation, sun, wind, dust, snow covering, etc.). The output will be engineering analysis of vendor environmental qualification data that may be substituted for testing. 
- Assess the ability of the material of the various barriers and structures to be decontaminated. The output will be the results of tests that measure the ease and effectiveness to decontaminate samples of barrier and structural material.

- Assess the ability of the barrier system to prevent contamination spread by leaking inward. The output will be the results of simulated contamination spread because the deliberate leaks in the various barriers.

- Assess the reliability, integrity, and ease of function of the barrier access port(s). The output will be as follows:

- Tests to measure case of entrance and exit through access ports.

- Tests to measure degree of simulated contamination spread because of access port leakage.

- Assess the ability to access all regions of each barrier for decontamination maintenance and/or repair. The output will be tests to measure the difficulty encountered with simulation maintenance and/or repair operations in various parts of barriers.

- Assess the ability of the contamination control system to rapidly detect airborne contaminants. The output will be to measure the

- Accuracy of airborne monitor system.

- Response time of the system.

- Assess the ability of the contamination control system to rapidly detect hot spots anywhere inside the barriers. The output will be to measure the

- Accuracy of the detection system.

- Response time of the detection system.

- Ability of the detection system.

- Assess the ability of the contamination control system to rapidly reduce airborne contamination and keep it below the limit that allows access to personnel wearing bubble suits. The output will be to measure the

- Capacity of the system to remove airborne contamination and maintain the level below the limit for personnel wearing bubble suits.

- Response time of the system to remove airborne from $200 \%$ of limit to the limit of contamination access granted to personncl wearing bubble suits. 
- Assess the ability of the contamination control system to remove or immobilize contamination hot spots anywhere inside any of the barriers. The output will be to measure the

- Mobility of the system to access all regions of the barriers.

- Extent that a contamination source is contained or removed.

- Response time of containment or removal of hot spots.

- Assess the ability of the contamination control system to be operated remotely and by personnel wearing bubble suits. The output will be to measure the performance of the following (remotely, locally in bubble suits, and locally without bubble suits) and then compare the results.

- Ability of the contamination control system to rapidly detect airborne contaminants.

- Ability of the contamination control system to rapidly detect hot spots anywhere inside the barriers.

- Ability of the contamination control system to rapidly reduce airborne contamination and keep it below limits that allow access by personnel wearing bubble suits.

- Ability of the contamination control system to remove or immobilize contamination hot spots anywhere inside the barriers.

- Assess the ability of the contamination control system to be repaired and/or maintained by personnel wearing bubble suits. The output will be to compare the performance of standard maintenance and or repair operations when personnel are wearing bubble suits and when they are not.

- Assess the ability of the contamination control system to function over the expected environmental extremes at the INEL. The output will be to verify system function over selected environmental extremes.

\subsection{Overburden Characterization and Removal Technology Demonstration Test Objectlves}

\subsubsection{Overburden Characterization Demonatration}

The objectives of the overburden characterization technology demonstration are to

- Assess the ability of the system to detect hazardous and radioactive hot spots. The output of the assessment will be to measure the system's ability to detect various strengths of hazardous and radioactive sources at various depths and types of soil. 
- Assess the ability of the system to accurately locate hazardous and radioactive hot spots. The output of this assessment will be to measure the accuracy of the system to locate hazardous and radioactive hot spots ( $x$ and $y$ position and $z$ depth).

- Assess the compatibility of the technology against the expected environmental conditions. The output of this assessment will be to measure system performance versus selected environmental variables (sun, dust, snow, mud, etc.).

- Assess the response time and cost of the technology to perform its function. The output of this assessment will be to measure

- How long it takes to gather data and how long it takes to get the data reduced.

- Total labor hours needed to gather data and get data reduced.

- Assess the system reliability in fulfilling its intended function. The output of this assessment will be documentation of mission degrading problems encountered because of equipment breakdown and design deficiencies.

\subsubsection{Removal Technology Demonstration}

Overburden removal technology demonstration test objectives are to

- Assess the ability of the system to retrieve overburden material to a specified depth. The output will be to measure the

- Accuracy and repeatability to which the system can be deployed and can remove overburden material.

- Response time of the system to deploy and remove a standard amount of overburden.

- Assess the ability of the system to retrieve hot spots (this feature could be part of the contamination control system). The output of this assessment will be to measure the

- Ability of the system to deploy to hot spot locations.

- Ability of the system to retrieve contaminated hot spots.

- Measure the response time for the system to deploy and retrieve hot spots.

- Assess the ability of the system to function remotely and locally with personnel in bubble suits. The output of this assessment will be to compare the system's performance in detecting hazardous and radioactive hot spots at various depths and types of soil, remotely and locally and locally with personnel in bubble suits.

- Assess the ability of the system to accommodate acces : by personnel wearing bubble suits for repair and/or maintenance operations. The output of this assessment will be comparison of 
typical repair or maintenance operations by personncl wearing bubble suits or not wearing bubble suits.

- Assess the ability of the sysiem to function over the expected environmental conditions. The output of this assessment will be to measure the system's performance versus selected environmental variables (temperature, snow, inud, etc.).

- Assess the system's reliability in fulfilling its intended function. The output of this assessment will be documentation of the mission degrading problems because of equipment failure and design deficiencies.

\subsection{Retrleval Technology Demonstration Test Objectives}

The test objectives of the retrieval technology demonstration are to

- Assess the ability of the system to commence operations through the use of deployment and maneuvering. The output of this assessment will be the

- Accuracy and repeatability with which the system performs for several different test deployments.

- Response time of the system in performing the various test deployments.

- Assess the ability of the system to deploy the equipment necessary to commence operations. The output will be the measurement of the system's performance in deploying a variety of equipment to different locations.

- Assess the ability of the system to move and stabilize oversize waste objects. The output of this assessment will be the measurement of the system's performance in moving oversize waste objects about the waste pit.

- Assess the ability of the system to excavate and convey buried waste. The output of this assessment will be to

- Measure production rates for different simulated waste.

- Document any kind of system limitations that impair excavation and conveyance function.

- Assess the ability of the system to detect hot spots (hazardous or radioactive) and stabilize them. The output of this assessment will be to

- Measure the system's sensitivity in detecting various hazardous or radioactive sources.

- Demonstrate the system's ability to stabilize these sources with shiclding or fixant to reduce radiation or contamination spread. 
- Assess the ability of the system to function when operating with the use of personnel wearing bubble suits or as a remote operation. The output of this assessment is the comparison of the system's performance between remote, local bubble suit, and local nonbubble suit operations.

- Assess the ability of the system to be maintained and/or repaired by personnel wearing bubble suits. The output for this assessment is comparison of repair and/or maintenance operations between operations with personnel wearing bubble suits and not wearing bubble suits.

- Assess the ability of the system to function over the expected environmental conditions. The output for this assessment is the measurement of the system's performance versus selected environmental variables (temperature, snow, mud, etc.).

- Assess the reliability of the system to fulfill the intended function. The output for this assessment will be documentation of mission degrading problems because of equipment failures and design deficiencies.

\subsection{Treatment Technology Demonstration Test Objectlves}

The test objectives for treatment icchnology demonstration are as follows:

- Assess the ability of the treatment in preventing criticality. The output will be to measure the ability of the system to dilute, dismember, or poison critical mass situations.

- Assess the ability of the system to be operationally safe from explosion, fires, radiation, or hazardous exposure. The output will be to measure the ability of the system to mitigate anticipated explosion, fire, radiation, or hazardous situations in the input waste feed.

- Assess the ability of the system to destroy organic material. The output will be to measure the organic content of processed waste over the range of expected organic concentration in the input waste feed.

- Assess the ability of the system to achieve volume reductions. The output will be to measure the extent of processed waste volume reduction over a range of input waste feed.

- Assess the ability of the system to be repaired and/or maintained through operations by personnel wearing bubble suits. The output for this assessment will be comparison of repair and/or maintenance operations between personnel wearing bubble suits and personnel not wearing bubble suits.

- Assess the reliability of the system in fulfilling its intended function. The output for this assessment will be documentation of mission degrading problems because of equipment failure and design deficiencies. 


\section{REFERENCES}

1. EG\&G Idaho, Inc., INEL Operable Unit 7-13 Retrieval/Ex Situ Thermal Treatment Configuration Options Report, EGG-WTD-10204, Revision 0, July 1992.

2. EG\&G Idaho, Inc., Buried Waste Integrated Demonstration Program Technology Test Plan Guidance, EGG-WTD-9800, Revision 0, February 1992.

3. University of California Research Laboratory, Design and Evaluation Guidelines for Department of Energy Facilities Subjected to Natural Phenomenon Hazard, UCRL-15910, October 1989.

4. U. S. Department of Energy Idaho Field Office, DOE-ID Architectural Engineering Standards, September 1991.

5. U. S. Department of Energy Idaho Field Office, Operational Safety Design Criteria Manual, ID12044, April 1985.

6. EG\&G Idaho, Inc., "BWID System Requirements," Technology Design File, SA-2.0, January 7, 1992. 


\section{Appendix A}

\section{FY-93 Technology Test Objectives}




\section{Appendix A}

\section{FY-93 Technology Test Objectives}

The system test and high-level target objectives for the Buried Waste Integrated Demonstration (BWID) core system have been detailed in previous sections of this document. Various technologies have been selected for development and demonstration by the BWID to satisfy these objectives. This section will provide further detail on technology-specific test objectives for the fiscal year (FY) 1993 BWID core system demonstrations. All objectives being investigated by the demonstration technologies are described.

The procedures and approaches for satisfying the FY-93 technology-specific test objectives are described in the individual technology test plans.

\section{A.1 Waste Characterization}

\section{A.1.1 Remote Characterization System}

The remote characterization system will

- Determine the system's accuracy and repeatability in locating the vertical waste pit boundaries $( \pm 2 \mathrm{ft})$

- Determine the system's accuracy and repeatability in locating the depth to the basalt at the waste pit boundaries $( \pm 2 \mathrm{ft})$

- Determine the system's accuracy and repeatability in locating the depth of the overburden and/or waste interface $( \pm 2 \mathrm{ft})$

- Assess the system's ability to detect and locate any transuranic (TRU) and/or hazardous chemical hot spots

- Assess the system's ability to function in the Cold Test Pit (CTP) environmental conditions

- Assess the response time and cost to characterize the pit

- Evaluate the control system (remotely, manually, and with personnel wearing bubble suits)

- Evaluate the positioning system (precision)

- Evaluate the camera system (environmental effects and adequacy)

- Evaluate the sensor system (interference and interaction)

- Evaluate the data communications system (range, reliability, and interference) 
- Assess the system's reliability

- Demonstrate the feasibility of remote characterization of buried waste.

\section{A.1.2 Digface Characterization Syotem}

The digface characterization system will

- Determine the accuracy and repeatability in locating the depth of the overburden/waste interface

- Assess the ability to detect and locate any TRU and/or hazardous chemical hot spots

- Assess the system's ability to function in the environmental conditions at the Idaho National Engineering Laboratory (INEL)

- Assess the response time and cost to characterize the pit

- Evaluate the positioning system (precision)

- Evaluate the sensor system (interference and interaction)

- Assess the system's reliability.

\section{A.1.3 Rapid Monttoring Unit}

The rapid monitoring unit will

- Evaluate the system's ability to quantify the various types of contamination samples

- Evaluate the system's ability to deploy and function in the CTP environmental conditions (temperature, dust, and dirt surface)

- Evaluate the production rates for each of the various sample types

- Evaluate the mobility of the continuous air monitor (CAM) and the ability to deploy (temperature, dust, and dirt sloped surface)

- Evaluate the ability to retrieve and/or replace the CAM filter

- Evaluate the ability to service the deployed equipment

- Evaluate the reliability of the various system components

- Measure the generation of additional waste (hazardous or radioactive) during operation 
- Evaluate the measurement system (sensitivity, repeatability, uncertainty, and confidence level)

- Determine the lower limits of detection in field conditions.

\section{A.2 Belowgrade Isolation}

\section{A.2.1 Waste Isolation Demonstration (Revised to an Engineering Deaign Study)}

The waste isolation demonstration will

- Install in INEL environment (time to stage and time to install)

- Anchor to the buried basalt layer (reliability of the method)

- Evaluate the ability to support an abovegrade containment structure

- Assess the structural integrity, based on INEL earthquake conditions (design accident condition calculations and actual test).

\section{A.3 Abovegrade Contalnment}

\section{A.3.1 Contamination Control Unit}

The containment control unit will

- Evaluate the ability to deploy and function in the CTP environmental conditions

- Evaluate the ability to apply immobilization materials

- Evaluate the range of application of immobilization materials

- Mcasure the degree of contamination immohilization

- Evaluate the compatibility of contamination control operations with other technological operations

- Evaluate the reliability of the system in the CTP environmental conditions

- Evaluate the extent that additional waste is generated. 


\section{A.3.2 Fixation of Soll Surface Contamination Uaing Natural Polyeaccharide}

The fixation of soil surface contamination using natural polysaccharide will

- Evaluate the effectiveness of the material used effectively in the waste remediation environment

- Evaluate the response time and the material's ability to immobilize surface contamination or removing airborne contamination

- Evaluate the extent, if any, that the material is incompatible with other necessary functions during waste retrieval operations

- Evaluate the extent, if any, that the material generates additional waste volume or mass.

\section{A.4 Overburden Characterization/Removal}

\section{A.4.1 Remote Characterization System}

The remote characterization system will

- Determine the accuracy and repeatability in locating the depth of the overburden and/or waste interface

- Assess the ability to detect and locate any TRU and/or hazardous chemical hot spots

- Assess the system's ability to function in the CTP environmental conditions

- Assess the response time and cost to characterize the pit

- Evaluate the control system (remotely, manually, and with personnel wearing bubble suits)

- Evaluate the positioning system (precision)

- Evaluate the camera system (environmental cffects and adequacy)

- Evaluate the sensor system (interference and interaction)

- Evaluate the data communications system (range, reliability, and interference)

- Assess the system's reliability

- Demonstrate the feasibility of remote characterization of buried waste. 


\section{A.4.2 Digface Characterization System}

The digface characterization system will

- Determine the accuracy and repeatability in locat ig the depth of the overburden/waste interface $( \pm 2 \mathrm{ft})$

- Assess the ability to detect and locate any TRU and/or hazardous chemical hot spots

- Assess the system's ability to function in the CTP environmental conditions

- Assess the response time and cost to characterize the pit

- Evaluate the positioning system (precision)

- Evaluate the sensor system (interference and interaction)

- Assess the system's reliability.

\section{A.4.3 Gantry Crane Characterization Syatem}

The Gantry crane characterization system will

- Assess the system's ahility to function in lahoratory conditions

- Evaluate the positioning system (precision)

- Evaluate the sensor system (interference and interaction)

- Assess the system's reliability.

\section{A.4.4 Remote Excavation System}

The remote excavation system will

- Determine the precision in removing overburden layers of specified thickness

- Determine the overburden removal rate and time to deploy the system

- Evaluate the system for contamination spread

- Assess the system's ahility to deploy to specific areas to remove hot spots in the overburden

- Evaluate the control system (remotely, manually, and with personnel wearing bubble suits) for the backhoe and front end loader

- Evaluate the positioning system (precision) 
- Evaluate the camera system (environmental effects and adequacy)

- Determine the system's reliability.

\section{A.4.5 Vendor Demonatration of Overburden Removal (Sonsub, Inc.)}

The vendor demonstration of overburden removal will

- Determine the precision in removing overburden layers of specified thickness

- Determine the overburden removal rate and time to deploy the system

- Evaluate the system for contamination spread

- Evaluate the system for conversion to remote operation

- Determine the system's reliability.

\section{A.5 Retrieval}

\section{A.5.1 Romote Excavation 8yetom}

The remote excavation system will

- Determine the precision of the system in deploying 10 and mancuvering at a waste site

- Determine the retricval rate and time to deploy

- Evaluate abovegrade retrieval and stability of the excavator above the excavation site

- Assess the ability of the system to function in the CTP environmental conditions

- Evaluate the control system (remotely, manually, and with personnel wearing bubble suits) for the backhoe and front end loader

- Evaluate the positioning system (precision)

- Evaluate the camera system (environmental cffects and adequacy)

- Determine the system's reliability.

\section{A.5.2 Retrleval Vendor Demonatration (Caterpillar, Inc.)}

The retrieval vendor demonstration will

- Determine the precision of the system in deploying to and maneuvering at a waste site 
- Evaluate end effector efficiency using conventional excavation equipment at $80 \mathrm{yd}^{3}$ of heterogeneous waste per day

- Evaluate both abovegrade and belowgrade retricusl

- Evaluate the ease of remotizing the equipment

- Determine the system's reliability.

\section{A.6 Treatment}

\section{A.6.1 Thermal Treatment with Maltere}

The thermal treatment with melters will

- Evaluate the ability of the process to accommodate the expected variation of waste form inputs (metals, organic, low vapor pressure metals, TRU, hazardous, contaminated soil, large objects, etc). This will include determining the limitations of the process (maximum or minimum values). This will result in determination of input requirements for the process and the resulting outputs.

- Evaluate the ability of thermal treatment to process BWID standard waste streams. Five waste streams are proposed as standard types for technology evaluations. These are (a) soil only, (b) high-metals content waste, (c) high-combustibles content waste, (d) sludge wastes, and (e) nominal content waste."

- Evaluate the ability of the process to generate the acceptable forms of waste output (tapped metal, glass that captures all TRU and meets Toxicity Characterization Leaching Procedure, destruction of organic material, volume reduction, etc). This will also include determining the effects of scaling-up the process to a full-scale facility.

- Evaluate the production rates of the process.

- Evaluate the offgas production for the process (as related to the variation of input waste, process chemistry, etc.).

- Evaluate and compare the performance of the process to existing baseline technologies.

a. S. O. Bates, Definition and Composition of Standard Waste Streams for Evaluation of Buried Waste Integrated Demonstration Treatment Technologies, EG\&G Idaho, Inc., EGG-WTD-10660, April 1993. 


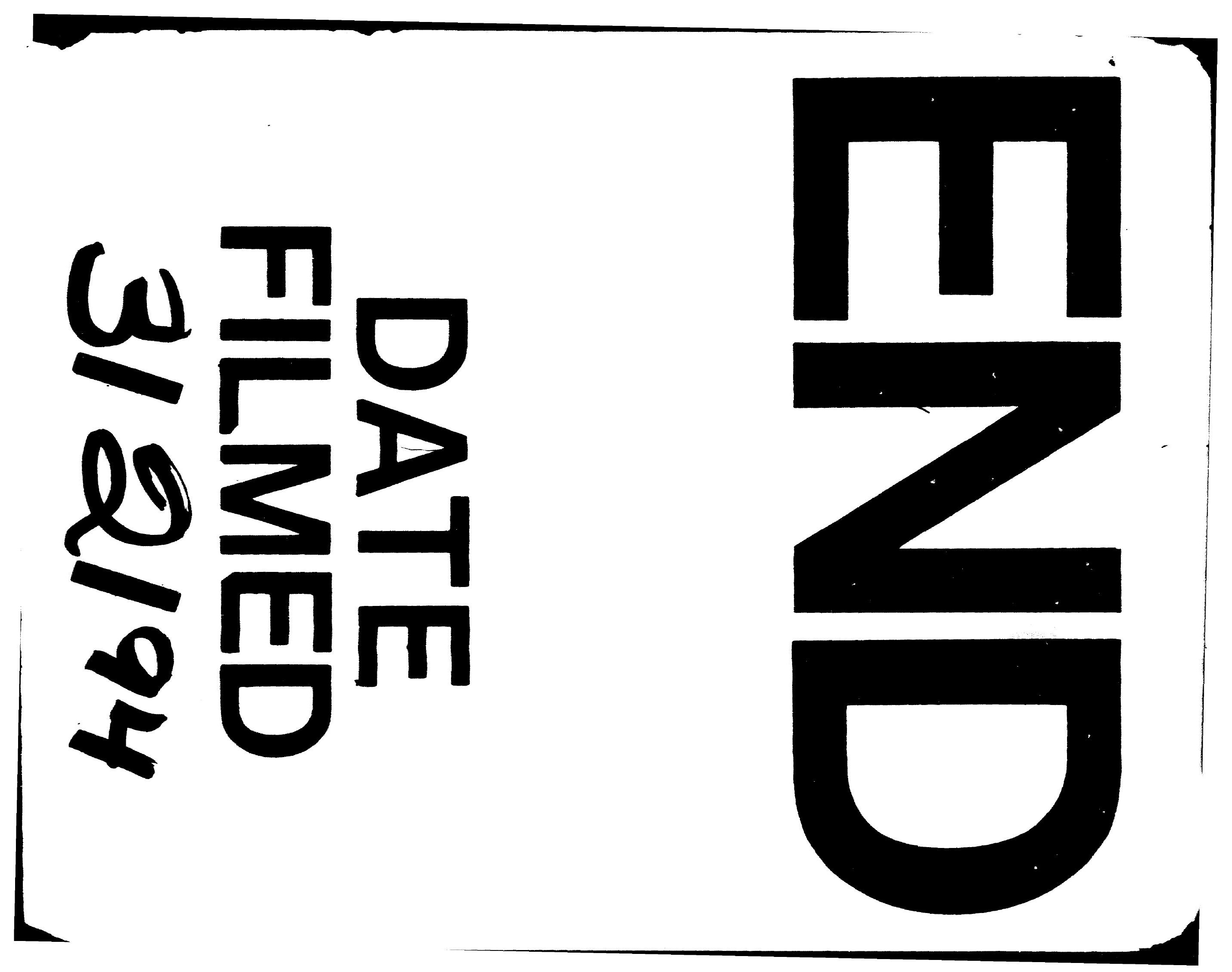


$\mid$ 